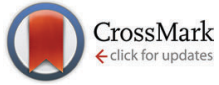

Cite this: Chem. Commun., 2014, 50, 10049

Received 11th May 2014 Accepted 3rd July 2014

DOI: $10.1039 / \mathrm{c} 4 \mathrm{cc} 03548 \mathrm{~h}$

www.rsc.org/chemcomm

\title{
Bio-specific and bio-orthogonal chemistries to switch-off the quencher of a FRET-based fluorescent probe: application to living-cell biothiol imaging $\dagger$
}

\author{
C. Egloff, ${ }^{a}$ S. A. Jacques, ${ }^{a}$ M. Nothisen, ${ }^{b}$ D. Weltin, ${ }^{c}$ C. Calligaro, ${ }^{c}$ M. Mosser, ${ }^{a}$ \\ J.-S. Remy ${ }^{\mathrm{b}}$ and A. Wagner*a
}

\begin{abstract}
We report the first molecular system that is responsive to both a bio-specific and a bio-orthogonal stimulus. This dual activation process was applied to the design of a biothiol-specific FRETbased fluorescent probe that could be turned-on via an original concept of quencher bleaching.
\end{abstract}

The field of chemistry in living organisms has long been focused on fine tuning of structural motifs' reactivity in order to achieve chemo-selective reaction with biological substrates such as an endogenous reactive metabolite, an amino acid, a DNA sequence, a ROS or acidic $\mathrm{pH}$. This type of biospecific chemistry has led to important developments in various domains such as imaging probes, ${ }^{1}$ pathology specific pro-drugs ${ }^{2}$ or advanced biomaterials. ${ }^{3}$ The idea of using exogenous reactants to trigger a chemical reaction in a living organism (bio-orthogonal reaction) appeared more recently and has nevertheless gained much interest. Among the landmark studies, Meggers ${ }^{4}$ and later Bradley ${ }^{5}$ showed that organometallic catalysts were able to mediate intracellular bond breaking and bond forming processes. Likewise, Bertozzi, ${ }^{6}$ Weissleder, ${ }^{7}$ and others pioneered the in vivo use of bioorthogonal $\mathrm{Cu}$-free click reactions.

An attractive goal to extend the scope of such bio-functional chemistries would now be to combine into a single molecular system both the capabilities to react with an endogenous metabolite (bio-specific reaction) and an exogenous reagent (bioorthogonal reaction). Such an endeavour relies on the chemist's ability to tweak the reactivity of functional groups and reagents in order to make them functioning under the particular constraints of complex biological media. For instance, such a molecular system

\footnotetext{
${ }^{a}$ Laboratory of Functional Chemo Systems, UMR 7199, CNRS-UdS, LABEX MEDALIS, UMR 7199 UdS/CNRS, Faculty of Pharmacy, 74 Route du Rhin, 67401 Illkirch-Graffenstaden, France.E-mail: alwag@unistra.fr; Fax: +33-368-854-297

${ }^{b}$ Laboratory V-SAT, UMR 7199, CNRS-UdS, LABEX MEDALIS, UMR 7199 UdS/CNRS, 74 Route du Rhin, 67401 Illkirch-Graffenstaden, France

'Phytodia SAS, Pôle API, Boulevard Sebastian Brant, 67412 Illkirch-Graffendstaden, France

$\dagger$ Electronic supplementary information (ESI) available. See DOI: 10.1039/c4cc03548h
}

should demonstrate water solubility, water stability, fast reaction kinetics at low concentration, bio-specificity and low toxicity. These stringent operating constraints as well as the precise bio-selectivity window required for such dual mode of activation make their development an attractive challenge for organic chemists.

In this communication, we report our study on $N$-(dicyanomethylene)aniline oxide that we found to be bio-specifically reactive towards endogenous biothiols and bio-orthogonally reactive towards sodium dithionite, a bio-compatible exogenous reagent. ${ }^{8}$ We also found that reaction with any of the above stimuli resulted in a strong hypsochromic shift of $\mathrm{N}$-(dicyanomethylene)aniline absorption. Based on this combination of chemo and bio-functionalities, we report a novel concept of a FRET probe which can be activated by either bio-specific or bioorthogonal bleaching of its quencher (Fig. 1).

Pro-fluorescent probes in complex biological media are activated via bio-specific reactions involving biothiols such as Michael additions, ${ }^{9}$ aromatic nucleophilic additions, ${ }^{10}$ thiazolidine ring formation, ${ }^{11}$ sulfonamide or sulfonate ester cleavage, ${ }^{12}$ disulfide cleavage and addition-elimination that activates FRET-based probes. ${ }^{13}$

It is noteworthy that even though the reported activation mechanisms have allowed some degree of biospecific activation

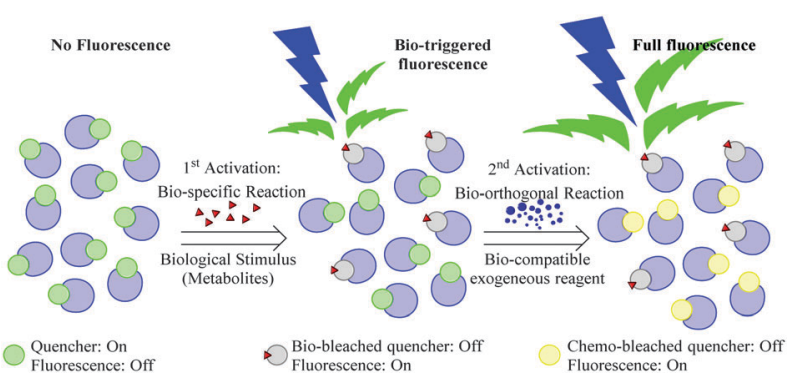

Fig. 1 Principle of a FRET-based probe with a biologically and chemically bleachable quencher. Metabolite-specific reaction shifts the quencher's absorption towards lower wavelengths and thus switches fluorescence on. Further treatment with a bio-compatible exogenous reagent results in complete bleaching of the quencher and consequently reveals the inactivate probes. 

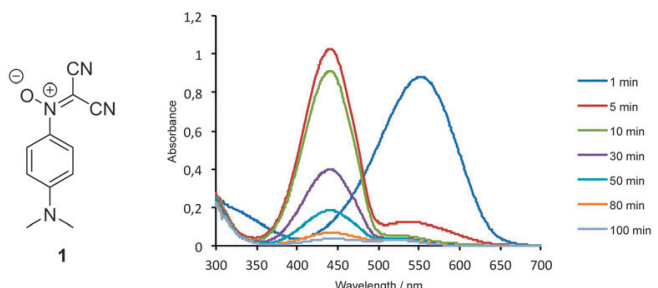

Fig. 2 Structure of nitrone 1 and absorption spectra of $1(50 \mu \mathrm{M})$ upon addition of Cys (1 mM) in phosphate buffer $(0.1 \mathrm{M}, \mathrm{pH} 7.4)$ at $1,5,10,30,50$, 80 and $100 \mathrm{~min}$.

to be obtained, none of them is compatible with subsequent activation with an exogenous bio-orthogonal reagent. Following reactivity screening, we have found that $N$-(dicyanomethylene)aniline oxide 1 (see Fig. 2), synthesized from nitroso aniline and tetracyanoethylene, exhibits suitable features to become an effective chemo-bio-bleachable quencher. ${ }^{14}$

Firstly, nitrone 1 showed a maximum absorption at $\lambda_{\max }=$ $552 \mathrm{~nm}$ (Fig. S1, ESI $\dagger$ ). Such a high maximum absorption wavelength overlaps with the emission spectrum of the tetramethylrhodamine (TAMRA), a widely used fluorophore that absorbs at $\lambda_{\max }=550 \mathrm{~nm}$ and emits at $\lambda_{\max }=580 \mathrm{~nm}$. Secondly, we found that upon treatment of nitrone $1(50 \mu \mathrm{M})$ with Cys $(1 \mathrm{mM})$ in phosphate buffer $(0.1 \mathrm{M}, \mathrm{pH} 7.4)$ the absorption band at $552 \mathrm{~nm}$ almost instantaneously disappeared with the concomitant and transient appearance of a new absorption band at $442 \mathrm{~nm}$ corresponding to the formation of a Cys-adduct (Fig. 2). This shift of the maximum absorption peak would represent a good fluorescence turn-on process of a nitrone-TAMRA FRET probe. Along with this change in absorption, a solution of nitrone 1 turned from dark purple to colourless (Fig. S4, ESI $\dagger$ ). Thirdly, the absorbance of compound $\mathbf{1}$ was instantaneously neutralized upon treatment with sodium dithionite in phosphate buffer (0.1 M, pH 7.4). This would be a smooth chemo-bleaching process of the corresponding nitrone-TAMRA FRET probe. Finally, MTT assays showed no inherent toxicity of nitrone 1 in HaCaT cells under physiological conditions (Fig. S5, ESI $\dagger$ ).

Synthesis of the nitrone-TAMRA FRET probe 7 started with the preparation of intermediate 2 (Fig. 3). Amine alkylation between $\mathrm{N}$-methylaniline and methyl-4-bromobutyrate gave compound 2. Nitrosation with sodium nitrite led to nitroso derivative 3. After saponification, $\mathbf{4}$ reacted with tetracyanoethylene (TCN) to give $\mathbf{5}$. Finally, coupling of 5 with TAMRA amine 6 gave the turn-on fluorescent probe 7 after purification by semi-preparative HPLC.

To assess the chemoselectivity of $\mathrm{N}$-(dicyanomethylene)aniline oxide moiety activation, probe $7(1 \mu \mathrm{M})$ was treated with various biological analytes $(5 \mathrm{mM})$ including amino acids, oxidizing and reducing agents, metal ions, glucose, nucleosides, ascorbic acid and thiols (Cys, Hcy, and GSH) in phosphate buffer (0.1 M, pH 7.4) (Fig. S10, ESI $\dagger$ ). The results demonstrated a significant fluorescence increase at $580 \mathrm{~nm}$ only upon reaction with thiol derivatives. With all the other analytes, no real fluorescence emission enhancement was observed. This thiol-specific reactivity was further confirmed by inhibiting the reaction with iodoacetate, a thiol-alkylating agent (Fig. S11, ESI $\dagger$ ). Next, our probe 7 was reacted with increasing equivalents of cysteine and a

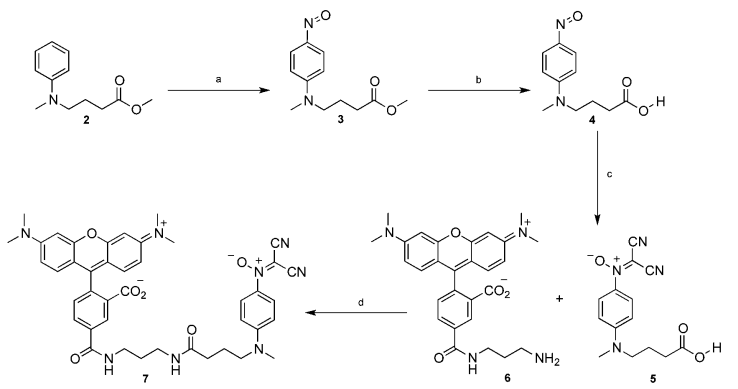

Fig. 3 Synthetic pathway for the formation of probe 7. Reagents and conditions: (a) $\mathrm{NaNO}_{2}, \mathrm{HCl}, \mathrm{CH}_{3} \mathrm{OH}, 0{ }^{\circ} \mathrm{C}, 30 \mathrm{~min} \rightarrow 30{ }^{\circ} \mathrm{C}, 4 \mathrm{~h}(38 \%$ ); (b) $\mathrm{NaOH}$, $\mathrm{CH}_{3} \mathrm{OH}$, RT, overnight (87\%); (c) TCN, DMF, RT, overnight (15\%); (d) EDC, $\mathrm{HOBT}, \mathrm{Et}_{3} \mathrm{~N}, \mathrm{DMF}, \mathrm{RT}$, overnight (27\%).

concentration-dependent increase in fluorescence response was recorded. We calculated the detection limit for thiols of $50 \mathrm{nM}$ (Fig. S8, ESI $\dagger$ ). We also measured a quantum yield of fluorescence of $15 \%$ upon activation with cysteine (Fig. S12, ESI $\dagger$ ). Bio-specific and bio-orthogonal activation of probe 7 was then studied in living cells. Probe $7(40 \mu \mathrm{M})$ was incubated with normal embryonic fibroblast 3T3 cells for $1 \mathrm{~h}$ and with 3T3 cells, pre-treated with $\alpha$-lipoic acid $(500 \mu \mathrm{M})$ for $48 \mathrm{~h}$. The purpose of $\alpha$-lipoic acid (ALA) is to increase the intracellular level of reduced GSH. ${ }^{15}$ Fluorescence emission was measured using a microplate reader (Fig. 4).

A sevenfold increase of intracellular fluorescence intensity was observed in ALA treated cells compared to non-treated cells. Then, ALA-3T3 cells were further treated with $N$-methylmaleimide (NMM) to decrease the level of free thiols within the cells by electrophilic alkylation and with buthionine sulfoximine (BSO), a specific inhibitor of $\gamma$-glutamylcysteine synthetase and therefore a GSH synthesis inhibitor. ${ }^{16}$ Under both conditions fluorescence intensity was found to be equivalent to that of untreated cells, thus indicating that activation of probe 7 was indeed descriptive of the intracellular level of free biothiols.

To validate the second mode of activation of probe 7 , namely bio-orthogonal chemical bleaching, sodium dithionite $(10 \mathrm{mM})$ was added to each one of the above-described assays (Fig. 5).

Finally, cells treated with probe 7 were imaged using confocal laser scanning microscopy. Cells were treated with blue

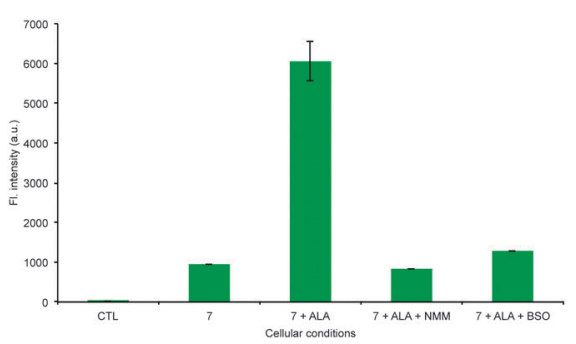

Fig. 4 Fluorescence of probe $7(1 \mu \mathrm{M})$ incubated for $1 \mathrm{~h}$ with $3 T 3$ cells, treated under various conditions: $\mathrm{CTL}=$ untreated $3 \mathrm{~T} 3$ cells; $7=$ probe 7 with non-treated cells; $7+A L A=$ probe 7 with cells pre-treated for $48 \mathrm{~h}$ with ALA $(500 \mu \mathrm{M}) ; 7+\mathrm{ALA}+\mathrm{NMM}=$ probe 7 with cells pre-treated for $48 \mathrm{~h}$ with ALA $(500 \mu \mathrm{M})$, then treated for 30 min with NMM $(500 \mu \mathrm{M})$; $7+\mathrm{ALA}+\mathrm{BSO}=$ probe 7 with cells pre-treated for $48 \mathrm{~h}$ with ALA $(500 \mu \mathrm{M})$ then treated for $30 \mathrm{~min}$ with BSO $(100 \mu \mathrm{M})$. Data were measured using a microplate reader (excitation filter $530 / 25 \mathrm{~nm}$; emission filter $590 / 35 \mathrm{~nm}$ ). 


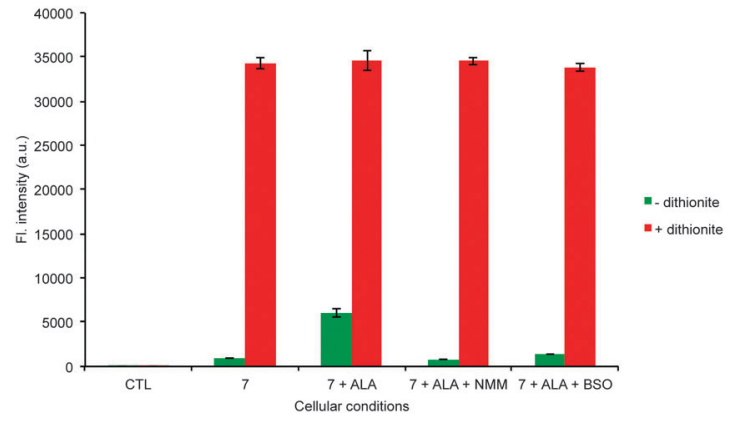

Fig. 5 Fluorescence of $\mathbf{7}$ in $3 T 3$ cells under various conditions before (green) and after (red) addition of dithionite $(10 \mathrm{mM}) . \mathrm{CTL}=$ untreated 3T3 cells; 7 = probe 7 with untreated cells; $7+$ ALA = probe 7 with cells pretreated for $48 \mathrm{~h}$ with ALA $(500 \mu \mathrm{M}) ; 7+\mathrm{ALA}+\mathrm{NMM}=$ probe 7 with cells pre-treated for $48 \mathrm{~h}$ with ALA $(500 \mu \mathrm{M})$ then treated for $30 \mathrm{~min}$ with NMM $(500 \mu \mathrm{M}) ; 7+\mathrm{ALA}+\mathrm{BSO}=$ probe 7 with cells pre-treated for $48 \mathrm{~h}$ with ALA $(500 \mu \mathrm{M})$ then treated for 30 min with BSO $(100 \mu \mathrm{M})$.
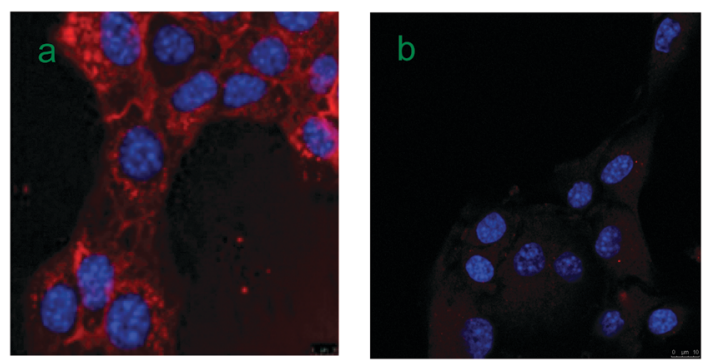

Fig. 6 Merged blue and red fluorescence images of living BNL CL.2 cells. (a) BNL CL. 2 cells were incubated with $1 \mu \mathrm{M}$ of $\mathbf{7}$ for $1 \mathrm{~h}$, then with Hoechst $33258\left(5 \mu \mathrm{g} \mathrm{mL}^{-1}\right)$ for $30 \mathrm{~min}$. Fluorescence image of BNL CL. 2 cells from the blue and the red channels. (b) BNL CL.2 were pretreated with ALA $(500 \mu \mathrm{M})$ for $48 \mathrm{~h}$, then with NMM $(500 \mu \mathrm{M})$ for $20 \mathrm{~min}$ and finally incubated with $1 \mu \mathrm{M}$ of $\mathbf{7}$ for $1 \mathrm{~h}$ and with Hoechst 33258 for $30 \mathrm{~min}$.

Hoechst-33258 dye to localize their nuclei. An intense intracellular fluorescence was present in the cytosol. The recorded images reveal that the probe can penetrate the cell membrane and is present throughout the cytosol (Fig. 6a). As a control, cells were treated with NMM prior to the addition of probe 7 . As expected in that case, only very weak fluorescence could be observed (Fig. 6b). This shows that, in the absence of free biothiol, none of the other components of biological media activates the probe, thus illustrating the good bio-stability and bio-selectivity of the $\mathrm{N}$-(dicyanomethylene)aniline oxide motif.

In summary, we have reported the first molecular system that is responsive to both a bio-specific and a bio-orthogonal stimulus. This was visualized via activation of a FRET probe through an original mechanism of quencher bleaching. Such a combination of bio-functional reaction and quencher-based fluorescence activation expands the repertoire of the turn-on/off probe mechanism. It also illustrates one of the many-to-come possibilities of using biofunctional chemistry to investigate biological systems with compact and multi-functional molecular tools.

We are grateful for the financial support from Région Alsace and International Centre for Frontier Research in Chemistry (ICFRC). We thank Dr A. Klymchenko and Dr A. Specht for helpful discussion.

\section{Notes and references}

1 Y. Koide, Y. Urano, S. Kenmoku, H. Kojima and T. Nagano, J. Am. Chem. Soc., 2007, 129, 10324; H. Kobayashi, M. Ogawa, R. Alford, P. L. Choyke and Y. Urano, Chem. Rev., 2010, 110, 2620.

2 F. Kratz, I. A. Müller, C. Ryppa and A. Warnecke, ChemMedChem, 2008, 3, 20; J. Rautio, H. Kumpulainen, T. Heimbach, R. Oliyai, D. Oh, T. Järvinen and J. Savolainen, Nat. Rev. Drug Discovery, 2008, $7,255$.

3 D. Roy, J. N. Cambre and B. S. Sumerlin, Prog. Polym. Sci., 2010, 35, 278; J. A. Wolff and D. B. Rozema, Mol. Ther., 2008, 161, 8.

4 C. Streu and E. Meggers, Angew. Chem., Int. Ed., 2006, 45, 5645.

5 R. M. Yusop, A. Unciti-Brocetal, E. M. V. Johansson, R. M. SanchezMartın and M. Bradley, Nat. Chem., 2011, 3, 239.

6 K. W. Dehnert, J. M. Baskin, S. T. Laughlin, B. J. Beahm, N. N. Naidu, S. L. Amacher and C. R. Bertozzi, ChemBioChem, 2012, 13, 353; P. V. Changa, J. A. Preschera, E. M. Slettena, J. M. Baskina, I. A. Millera, N. J. Agarda, A. Loa and C. R. Bertozzi, Proc. Natl. Acad. Sci. U. S. A., 2010, 107, 1821.

7 N. K. Devaraj, G. M. Thurber, E. J. Keliher, B. Marinelli and R. Weissleder, Proc. Natl. Acad. Sci. U. S. A., 2012, 109, 4762.

8 G. Leriche, G. Budin, Z. Darwich, D. Weltin, Y. Mély, A. S. Klymchenko and A. Wagner, Chem. Commun., 2012, 48, 3224; J. M. Bergen, E. J. Kwon, T. W. Shenand and S. H. Pun, Bioconjugate Chem., 2008, 19, 377.

9 H. S. Jung, J. H. Han, T. Pradhan, S. Kim, S. W. Lee, J. L. Sessler, T. W. Kim, C. Kang and J. S. Kim, Biomaterials, 2012, 33, 8945; D. Kand, A. M. Kalle, S. J. Varma and P. Talukdar, Chem. Commun., 2012, 48, 2722; H. Zhang, P. Wang, Y. Yang and H. Sun, Chem. Commun., 2012, 48, 10672.

10 M. Zhang, M. Yu, F. Li, M. Z. M. Li, Y. Gao, L. Li, Z. Liu, J. Zhang, D. Zhang, T. Yi and C. Huang, J. Am. Chem. Soc., 2007, 129, 10322.

11 Z. Yang, N. Zhao, Y. Sun, F. Miao, Y. Liu, X. Liu, Y. Zhang, W. Ai, G. Song and X. Shen, Chem. Commun., 2012, 48, 3442; M. Hu, J. Fan, H. Li, K. Song, S. Wang, G. Cheng and X. Peng, Org. Biomol. Chem., 2011, 9, 980; J. O. Escobedo, S. Jiang, I. M. Warner, F. B. Dawan, K. Lian and R. M. Strongin, J. Am. Chem. Soc., 2004, 126, 438.

12 X. D. Jiang, J. Zhang, X. Shao and W. Zhao, Org. Biomol. Chem., 2012, 10, 1966; W. Jiang, Y. Cao and W. Wang, Chem. Commun., 2010, 46, 1944; J. Bouffard, Y. Kim, T. M. Swager, R. Weissleder and S. A. Hilderbrand, Org. Lett., 2008, 10, 37.

13 J. H. Lee, C. S. Lim, Y. S. Tian, J. H. Han and B. R. Cho, J. Am. Chem. Soc., 2010, 132, 1216; B. Zhu, X. Zhang, Y. Li, P. Wang, H. Zhang and X. Zhuang, Chem. Commun., 2010, 46, 5710; P. K. Pullela, T. Chiku, M. J. Carvan III and D. S. Sem, Anal. Biochem., 2006, 352, 265.

14 D. L. Lipilin, A. M. Churakov, S. L. Ioffe, Y. A. Strelenko and V. A. Tartakovski, Russ. Chem. Bull., 1997, 46, 617.

15 C. Hwang, A. J. Sinskey and H. F. Lodish, Science, 1992, 257, 1496; H. Moini, O. Tirosh, Y. C. Park, K. J. Cho and L. Packer, Arch. Biochem. Biophys., 2002, 397, 384.

16 O. W. Griffith and A. Meister, J. Biol. Chem., 1979, 254, 7558. 